\title{
Physical activity and cancer risk
}

\author{
Adrianne E. Hardman \\ Human Muscle Metabolism Research Group, Department of Physical Education, Sports Science and Recreation Management, \\ Loughborough University, Loughborough, Leicestershire LE11 3TU, UK
}

\begin{abstract}
Evidence is accumulating that high levels of physical activity are associated with a reduced risk of some cancers. This evidence is most consistent for colon cancer, which is reduced by 40-50\% among the most active individuals, compared with the least active. The effect is evident in men and women, and appears to be independent of important confounding factors. However, there may be important interactions with body fatness; a high BMI has been reported to be associated with an increased risk of colon cancer in sedentary men but not in physically-active men. Whilst the evidence on breast cancer is less consistent, case-control studies typically suggest a reduction of 25-30 \% among the most active women, although several studies have found no effect. Potential mechanisms include systemic influences and others relevant only to site-specific cancers. One unifying hypothesis is that physical inactivity reduces insulin sensitivity, leading to a growthpromotional environment which may facilitate neoplasia. The non-specific immune system may be improved by physical activity, possibly through the summative effects of repeated exercise bouts. Regular exercise, even at a recreational level, probably reduces exposure to oestrogen and thus decreases the risk of breast cancer. Increased colonic peristalsis, and thus reduced bowel transit time, might partly explain the lower risk of colon cancer in active people. Physical activity emerges as one of the few modifiable risk factors for some cancers and, as such, justifies further study.
\end{abstract}

\section{Physical activity: Cancer risk}

A large body of evidence shows that high levels of physical activity are associated with multifarious health benefits, e.g. a low risk of CHD, type II diabetes, hypertension and stroke (Pate et al. 1995). Only recently has it become clear that physical activity may also be associated with a reduced risk for the development of several common forms of cancer. Physical activity is a modifiable lifestyle characteristic, and so potentially one means for primary prevention. For this reason alone, it is important to examine the available evidence. The present review considers the findings of epidemiological surveys and discusses potential mechanisms.

\section{Epidemiology}

Marked international differences in incident rates exist for many common cancers, and data for migrants suggest that these differences may be largely attributable to environmental, rather than genetic, differences. For example, colo-rectal cancer seems to be particularly sensitive to changes in the environment: among immigrants and their descendants, incidence rates rapidly reach those of the host country (McMichael \& Giles, 1988). The adoption of a high-energy diet which is high in saturated fat has sometimes been proposed as the major determinant of such alterations to incidence rates. In the light of the evidence for a reduced risk for some cancers in physically-active people, an alternative hypothesis might be that the adoption of the sedentary lifestyle of the host country is at least as important.

Total exposure to the risk factor of sedentary living is invariably measured by recording its obverse, i.e. physical activity, and evaluation of this evidence should recognise the difficulty of measuring physical activity in surveys. Ideally, occupational work, recreational activity and daily living activities should all be determined, and it might be important to have data on the components of activity, frequency, intensity and duration. Decisions on the time periods in life (e.g. adolescence, adulthood, pre- or postmenopause) which should be investigated depend partly on 
understanding the underlying mechanisms, but these mechanisms are poorly understood. A particular problem with studies of physical activity and cancer risk is that few studies were established with this factor as the primary hypothesis.

\section{Colon cancer}

Colo-rectal cancer is the fourth most common incident cancer, and the second most common cause of cancer death in the USA. It occurs with approximately equal frequency among men and women. Established risk factors include a low consumption of fibre and folate, high consumption of animal fat, red meat and a family history of colon cancer (Potter, 1999). There is now substantial evidence that physical inactivity should be added to this list. Indeed, the relationship between physical activity and a reduced risk of colon cancer is among the most consistent in the epidemiological literature on colon cancer risk (Potter, 1999).

Activity has been measured by occupation and by leisuretime activities. In case-control studies this measurement was done using recall for a defined period before the diagnosis of colon cancer. Overall, these studies suggest a consistent inverse relationship between both occupational and leisure-time activity and colon cancer risk among both men and women. There are several indications that high levels of physical activity maintained over a long period constitute the strongest protection.

In a large multi-centre case-control study, lack of lifetime vigorous $(23-27 \mathrm{~kJ} / \mathrm{min})$ leisure-time physical activity was associated with 63 and $59 \%$ excess risk of colon cancer in men and women respectively (Slattery et al. 1997). Activity was assessed as energy expenditure, based on reported intensity and duration of activities at home, leisure and work for the referent year, 10 years ago and (for older participants) 20 years ago. Lifetime vigorous leisuretime activity was the only physical activity variable consistently associated with colon cancer.

A recent study in Italy found an odds ratio for those in the highest level of occupational physical activity (compared with the lowest) of 0.64 (95\% CI $0.44,0.93)$ for men and 0.49 (95\% CI 0.33, 0.72) for women (Tavani et al. 1999). No association was found for leisure-time activity. Theoretically, occupational activity could be the relevant factor defining disease risk because it may be relatively constant over long periods of life. However, as physicallydemanding jobs become less common, the range of occupational activity in a study population may be too narrow to reveal associations with cancer risk. In a much smaller Swiss study, both occupational and leisure-time activity were associated with a lower risk; the odds ratio was lower for occupational than for leisure-time activity, however $(0.44$ (95 \% CI 0.26, 0.73) v. 0.53 (95\% CI 0.33, 0.86); Levi et al. 1999).

In prospective studies measures of physical activity range from a single question about usual pattern of activity over $24 \mathrm{~h}$ in a few broad categories to detailed questionnaires completed twice with an interval of about 10 years. Experience from epidemiological studies of $\mathrm{CHD}$ showed that, when poor measures of activity were used, studies tended to underestimate its true impact (Powell et al. 1987).
The same may be true for surveys focused on the risk of cancer. Nevertheless, of eighteen cohort studies reviewed in 1997 (Colditz et al. 1997), seventeen found a reduction in risk similar to that observed in case-control studies.

Indications in the older literature were that the relationship between colon cancer risk and physical activity was stronger for men than for women. However, recent studies on women show a similar magnitude of risk reduction. For example, leisure-time activity has been associated with a reduced risk in the US Nurses Health Study (Martínez et al. 1997) and in a cohort of Norwegian women (Thune \& Lund, 1996). Among the nurses, engaging in activities of moderate intensity (i.e. walking at a normal or brisk pace) for $1 \mathrm{~h} / \mathrm{d}$ was associated with a $46 \%$ reduction in risk. This finding was reasonably consistent with the report from Norway where the equivalent of walking or bicycling for at least $4 \mathrm{~h} /$ week was associated with a $38 \%$ reduction in risk compared with the sedentary group (Thune \& Lund, 1996). The strongest effect observed was reported for Swedish men when occupational and leisure-time physical activity levels were combined (Gerharsson et al. 1988). Men in the highest category had a relative risk of 0.3 (95\% CI $0.1,0.8$ ) compared with men who were inactive at work and engaged in little recreational activity.

There is some indication of a dose-response relationship; among the Norwegian women referred to earlier, combining occupational and leisure-time physical activity revealed a significant relationship between risk of colon cancer and total physical activity (for trend, $P=0.04$; Thune $\&$ Lund 1996).

The issue of potential confounding factors is a difficult one. Individuals who are physically active may exhibit other lifestyle characteristics associated with a reduction in the risk of colon cancer. However, the strength of the effect of activity is not materially altered by controlling for other factors known to relate to colon cancer risk. For example, the Health Professionals Follow-up Study reported detailed analyses of potentially confounding factors (Giovannucci et al. 1995). Men who were highly active (highest quintile for total activity measured in MET-h, where MET is the unit of metabolic cost $\left(\mathrm{O}_{2}\right.$ consumption) of physical activity (1 MET is equivalent to the resting metabolic rate, assumed to be $3.5 \mathrm{ml} \mathrm{O}_{2} / \mathrm{kg}$ body mass per min) and MET-h is the sum of average time per week spent in each activity $\times$ MET value of each activity) ate less saturated fat, more fibre, were less likely to smoke, more likely to use multivitamins and had a lower BMI. After controlling for all these factors, as well as aspirin use and family history, their risk relative to sedentary men increased only slightly, from 0.44 (95\% CI $0.27,0.71)$ to $0.53(95 \%$ CI $0.32,0.88)$, and the inverse trend in risk with increasing activity remained statistically significant.

Physical activity does not, therefore, appear to be merely a marker for a healthier lifestyle, but exerts an independent protective effect on the risk of colon cancer. Protection does, however, appear to be limited to the colon. The association with high levels of physical activity is much stronger for the colon than it is for the rectum, where it is at best only very weakly associated (Lee et al. 1991; Thune \& Lund, 1996). This finding may explain the trend for studies that have not 
reported data separately for these two sites to find less strong relationships with physical activity.

Data from studies of the risk of colo-rectal adenoma (cancer precursors) and physical activity are concordant with the findings described earlier. Among both men (Neugut et al. 1996) and women (Giovannucci et al. 1996), individuals who are highly active have a significantly lower risk of adenoma. As in the studies with cancer as the outcome measure, obesity is associated with a higher risk of adenomas. For example, in the Nurses Health Study women in the highest quintile for energy expenditure in physical activity had only $57 \%$ of the risk of large adenoma observed in sedentary women (Giovannucci et al. 1996). Among the same population, a high BMI $\left(>29 \mathrm{~kg} / \mathrm{m}^{2} v .<21 \mathrm{~kg} / \mathrm{m}^{2}\right)$ markedly increased the risk (relative risk $2 \cdot 21$ (95\% CI $1.18,4 \cdot 16)$ ). One study found some protection from adenoma associated with recent but not past physical activity (Enger et al. 1997).

\section{Breast cancer}

The relationship between physical activity and the risk of breast cancer has been reviewed several times, most recently in 1998 (Friedenreich et al. 1998; Gammon et al. 1998). At that time a majority (fifteen of twenty-one studies) observed a lower risk in women who were physically active in recreational and/or occupational activities than in inactive women. Since then at least six further studies have been published, all but one of which found a lower risk in active women (Mezzetti et al. 1998; Levi et al. 1999; Rockhill et al. 1999; Verloop et al. 2000) or in a sub-group of active women (Moradi et al. 1999). The study which found no relationship examined data from younger women enrolled in the Nurses Health Study (Rockhill et al. 1998) and this finding is commented on below. The magnitude of the association ranged from a $10-60 \%$ reduction in risk for the highest activity levels measured to a 30-40\% increase in risk (Friedenreich et al. 1998). The greatest decrease in risk $(58 \%)$ was observed in a case-control study of recreational activity (Bernstein et al. 1994). One reason may be that these workers measured physical activity at several stages of life, deriving a measure of 'lifetime' activity. This suggestion is supported by the finding from a recent cohort study that the effect of activity was strongest in women who reported being physically active, assessed by two surveys, separated by an interval of several years (Thune et al. 1997). An alternative explanation, however, is that repeated assessment improves measurement precision by reducing misclassification. Occupational activity has been associated with more modest decreases in risk than observed for physically-active recreations but, as might be expected, classifying women according to both sources of activity showed a greater protective effect than that associated with recreational activity alone (Verloop et al. 2000).

There is insufficient evidence as yet to reach a conclusion on the dose-response aspects of the relationship between physical activity and the risk of breast cancer. This situation may be because data describing the different components of activity are insufficiently detailed. Several studies have, however, reported findings suggestive of greater decreases in risk with more activity. For example, in the Norwegian cohort study, the risk relative to sedentary women (adjusted for several potentially-confounding factors) was 0.93 for moderate recreational exercise $(\geq 4 \mathrm{~h} /$ week walking or bicycling) and 0.63 for regular exercise ( $\geq 4 \mathrm{~h} /$ week exercising to keep fit or engaging in vigorous training or competitive sports several times per week; Thune et al. 1997). In the recent study of Dutch women, risk was highest in women engaging in neither occupational nor recreational activity (referent group) and lowest among those with active occupations who also reported physically-active recreations (relative risk $0.58(95 \%$ CI $0.42,0.82)$ ), with intermediate overall levels of activity fitting into this dose-dependent pattern (Verloop et al. 2000). A similar trend was evident $(P=0.004)$ for cumulative (composite of five assessments) average hours per week of moderate or vigorous activity among US nurses (Rockhill et al. 1999).

What is clear is that a decrease in risk has commonly been observed with about $4 \mathrm{~h}$ of activity at a moderate level or above per week. The finding in the US Nurses Health Study that even $\geq 7 \mathrm{~h}$ of moderate or vigorous activity was associated with only a modest $(18 \%)$ reduction in risk (Rockhill et al. 1999) represents the most conservative estimate of the reduction which may be expected for the time invested in physical activity. One reason that the effect of recreational exercise was less strong among this group than among some other groups may be that the level of usual occupational physical activity in nurses may be rather high, reducing the effect of variable levels of recreational activity. This factor might also have contributed to the lack of even a suggestion of a protective effect of non-occupational activity in young women (25-42 years on entry) from this same cohort (Rockhill et al. 1998). Another explanation might involve the methods of measuring physical activity which, as pointed out by Bernstein \& Ross (1998), might permit nurses engaging in very short periods of activity, twice weekly to be classified as physically active. These issues serve to underline the complexity of such studies and help explain discrepancies in their findings.

Indeed, one factor which could explain the 'null' finding just referred to among younger nurses might be that the influence of physical activity differs according to hormonal status. It has been suggested that many incidences of breast cancer among premenopausal women might be attributable to 'highly penetrant gene mutations' and therefore less amenable to primary prevention through physical activity (Rockhill et al. 1999). Another possibility is the contrasting effect of body fatness on breast cancer risk in pre- and postmenopausal women; among premenopausal women a high BMI is associated with a reduced risk, whereas among postmenopausal women this factor increases risk. Theoretically, therefore, and assuming that physical activity exerts its protective effect partly through decreasing body fat levels, physical activity might be associated with a reduction in the risk of breast cancer only in older women. Against this possibility, however, is the fact that an inverse association with physical activity has been reported in both pre- and post-menopausal women. In addition, at least some studies which included both pre- and post-menopausal women found that the effect of exercise was either similar in both 
sub-groups (Rockhill et al. 1999) or stronger (Thune et al. 1997) in premenopausal women. More extensive data are required before this issue can be resolved.

Thus, the proposition that physical activity can reduce breast cancer risk is still unproven, with mixed results from epidemiological data. Case-control studies suggest typical reductions of $25-30 \%$ for the most active women, but several studies found little or no association, and two, one of them the Framingham cohort study, an increased risk (Dosemeci et al. 1993; Dorgan et al. 1994). One explanation for the disparity in results has been imprecision and lack of standardisation in the assessments of physical activity. However, detailed evaluation of the methods used in twenty studies (Ainsworth et al. 1998) found no association between precision of measures and study results.

\section{Other site-specific cancers}

Surveys have reported data related to physical activity and the incident rates of endometrial cancer, ovarian cancer, testicular cancer, prostate cancer and lung cancer but, of these sites, there is a reasonable body of evidence only for prostate cancer. Estimates of relative risk in about twenty studies reviewed in 1998 (McTiernan et al. 1998) are evenly distributed around 1.0, and indicate little or no effect of physical activity. Two recent prospective studies which measured recreational activity confirmed this conclusion (Giovannucci et al. 1998; Liu et al. 2000), but a third study found a protective effect on prostatic cancer of both occupational work (walking, and walking and lifting, but not heavy labour) and recreational activity (Hartman et al. 1998).

\section{Summary of epidemiology}

Compared with studies of CHD, it is difficult to evaluate possible confounding factors, examine potential doseresponse relationships and specified activities because the incidence of cancer on a site-specific basis is so much lower. Better instruments for measuring physical activity, particularly among women, are sorely needed. Since there are links with lifetime exposure to, for example, endocrine risk factors, these measurements need to encompass activity at difference stages in life.

\section{Potential mechanisms}

Survey data are inevitably inconsistent, particularly when describing characteristics like diet and physical activity which are notoriously difficult to measure. In assessing the plausibility of a link between the risk of specific cancers and physical activity it is important therefore to consider what the underlying biological mechanisms could be. Several mechanisms have been suggested, both systemic and sitespecific. Those mechanisms best supported by evidence are mentioned here.

\section{Systemic influences: body fatness and metabolic milieu}

Overweight, the inevitable outcome of a long-term positive energy balance, has long been recognised as a risk factor for hormone-related and other cancers. The effect of regular physical activity on the risk of colon and breast cancer may therefore be due in part to improved weight maintenance in active people. Although taking up physical activity is associated with only modest decreases in body mass and fatness (Ballor \& Keesey, 1991), there are recent reports (Williamson et al. 1993; Haapanen et al. 1997) that active individuals are much less likely to experience clinically significant weight gain in adulthood. This factor may be important, particularly for the risk of cancer of the breast where adult weight gain is a strong risk factor.

Despite the relationships with high BMI, cancer risk is not always associated with high total energy intake. For example, among seven prospective studies, none showed any relationship between risk of breast cancer and total energy intake (Hill, 1999). By contrast, twenty-three of twenty-nine studies of post-menopausal breast cancer showed a positive association with BMI (Hill, 1999). The association between the risk of colo-rectal cancer and overweight is also strong, yet few studies report an association with high energy intake. One interpretation of these observations is that cancer risk may be related as much to physical inactivity as to excess energy intake.

A recent report provides some insight into the interrelationships between risk of colon cancer, body fatness and physical activity (Slattery et al. 1997). These workers examined cancer risk within sub-groups classified by both BMI and physical activity level. At high levels of activity, risk was not influenced by BMI. By contrast, among inactive men and women BMI was an important indicator of risk which was strongest for those with low activity, high BMI and high energy intake. These findings show that among those individuals who are physically active, a high energy intake presents no risk. They suggest that energy balance per se may be associated with colon cancer, and that associated systemic metabolic influences on carcinogenesis may be involved.

The roles of energy intake, body mass and physical activity are clearly interrelated in the aetiology of at least some cancers. An explanation that unifies these three factors has been proposed, which involves systemic metabolic influences rather than local influences on particular organs. Physical activity, particularly in the presence of a low body fat level, is associated with a general metabolic milieu (low insulin, low plasma triacylglycerol concentration) which is less favourable to the growth of cancer in general, and perhaps colon cancer in particular. Insulin, and insulin-like growth factor, lead to a general stimulation of cellular growth. Thus, hyperinsulinaemia creates a growthpromoting milieu which might specifically benefit neoplastic cells (McKeown-Eyssen, 1994). This proposal fits with the observations that individuals with colon cancer have been reported to have a higher than expected prevalence of the metabolic syndrome (McTiernan et al. 1998). Insulin sensitivity is poor in individuals with high levels of abdominal fat (Després, 1994) and so it fits also with a report that waist circumference $(\geq 109 \mathrm{~cm} v .<89 \mathrm{~cm})$ and a high waist:hip ratio $(\geq 0.99 v .<0.90)$ were strong risk factors for colon cancer, even after adjustment for body mass and physical activity (Giovannucci et al. 1995). Links with body fat distribution might account for the fact that risk 
of high body mass is higher in men (who tend to accumulate abdominal fat) than in women (Phillips \& Snowdon, 1985). There may be links with hormone-related cancers. Elevated serum insulin concentration has been associated with the risk of breast cancer (McTiernan et al. 1998). Insulin-like growth factors, which stimulate cell turnover in most body tissues, have been associated with an increased risk of prostate and breast cancers.

\section{Improved immunosurveillence}

The immune system monitors the body for abnormal cells and antigens, and immune surveillance therefore has the potential to influence cancer formation by killing neoplastic cells. Experimental studies in animals suggest that exercise can prevent the incidence, progression or spread of experimental tumours. One mechanism by which physical activity may decrease cancer risk is therefore via effects on innate non-specific immune function. Exercise immunology is a developing field, and the working theory is that there exists a level of physical activity that results in enhanced immune function, leading to reduced infectious disease and maybe cancer incidence. The 'dose' of exercise may be critical, however, because there is evidence that overtraining and/or intense competition leads to immunosuppression. Thus, the relationship between exercise and immune function follows a 'J-shaped' curve, with the lowest risk among individuals who take regular moderate exercise (Woods et al. 1999).

Although this rationale has been articulated many times, there is little direct evidence in human subjects. Several small randomised experimental trials have found that moderate physical activity such as brisk walking reduces the number of sickness days due to upper respiratory tract infections (Nieman et al. 1990; Scanga et al. 1998). However, none of these studies found significant changes in resting immune function, i.e. no long-lasting effect of training. It has therefore been proposed that any beneficial effects on immunosurveillance and host protection that come from moderate activity probably arise from the repeated acute changes which occur transiently after each exercise session (Nieman \& Pedersen, 1999). These effects include changes to the number and functions of neutrophils and to the activity of natural killer cells (Nieman \& Pedersen, 1999). Some studies in vitro suggest that natural killer cell activity is reduced by a high concentration of oestrogen, so there may be a link between physical activity, innate immunity and breast cancer risk and exposure to this hormone.

\section{Hormone-related cancers}

Various indices of exposure to oestrogen are positively associated with the risk of breast cancer. These indices include early menarche, lack of lactation, late menopause and a high number (over the lifetime) of ovulatory cycles. One mechanism by which high levels of physical activity may protect against breast cancer is thus an effect on oestrogen exposure.

Girls participating in vigorous sports tend to have late menarche, although this may not be a cause and effect relationship if girls who reach menarche late are more likely than their peers to take up sports. However, disturbances of menstrual function with endurance (aerobic) exercise are well documented. For example, of twenty-eight untrained students who undertook an intensive programme of running, only four had a normal cycle; running led to low oestradiol concentrations, short luteal phases, loss of the normal positive feedback action of oestrogen and a high incidence of anovulation (Bullen et al. 1985). The exercise undertaken was intense, i.e. running $6.4 \mathrm{~km} / \mathrm{d}$, progressing to $16 \mathrm{~km} / \mathrm{d}$ as well as daily participation in $3.5 \mathrm{~h}$ of moderate-intensity sports activity. However, one study of cyclic ovarian function in women engaging in physically-active recreations, as opposed to a rigorous training programme, suggests that less-intense exercise may also have biologicallyimportant effects on exposure to oestrogen (Broocks et al. 1990). Physically-active women who ran between 20 and $30 \mathrm{~km} /$ week and also engaged in other activities such as gymnastics, dancing or tennis were compared with inactive controls. Six of seventeen in this group showed disturbed follicular development, and one showed luteal phase disturbance. However, even active women with apparentlynormal cycles had lower plasma concentrations of oestradiol than sedentary controls, an important finding in the context of the present discussion. Consequently, women who are physically active even at a recreational level probably have less exposure to oestrogen than their inactive counterparts.

Among post-menopausal women, decreased exposure to insulin may also link physical activity to a lower risk of breast cancer through effects on body fatness. By reducing weight gain after menopause, a recognised risk factor, activity may decrease circulating oestrogen concentrations by decreasing the conversion of adrenal androgens to oestrogens in adipocytes. Another factor which would be more important in post-menopausal women (because of the absence of the feedback mechanism regulating plasma oestrogen levels) might be an effect on sex hormonebinding globulin. This effect increases with physical activity (McTiernan et al. 1998), resulting in lower levels of free active hormone in the circulation.

\section{Gut transit time (colon cancer)}

One of the mechanisms proposed for the protective effect of physical activity on colon cancer is that bowel transit time decreases when individuals begin exercising, decreasing the exposure to carcinogens. To the author's knowledge, however, this observation is restricted to running (Cordain et al. 1986), which may differ in this respect from other forms of activity. A further limitation is that, although stool bulk is a good correlate of colo-rectal cancer risk, transit time is not a well-established risk factor for colon neoplasia. Another mechanism might involve exercise-induced changes to prostaglandins. Prostaglandin $\mathrm{E}_{2}$ increases the rate of colonic cell proliferation, especially in colonic neoplasms, and decreases colonic motility. In line with this hypothesis, it has recently been reported that level of leisure-time physical activity was inversely related to prostaglandin $\mathrm{E}_{2}$ concentration; a difference in activity level from $5 \cdot 2$ to $27.7 \mathrm{MET}$-h/week was associated with a $28 \%$ 
decrease in prostaglandin $\mathrm{E}_{2}$ concentration (Martínez et al. 1999).

\section{Summary}

Although there is a substantial body of evidence describing a variety of measures of physical activity, there is a dearth of information about specific activities, e.g. swimming, cycling or jogging. This is important for two reasons. First, for the potential of activity in primary prevention; some activities are less unattractive to individuals who are presently sedentary than others. Second, for understanding of the mechanisms involved. For example, if mechanisms underlying the protective effect of physical activity on the risk of colon cancer include increased colonic peristalsis, one might expect jogging but not cycling to be effective; if the effect is primarily systemic, involving improvements to insulin sensitivity, then the energy expended would be a more important determinant than the mode of exercise.

On the positive side, there are indications that the level of activity associated with statistically significant decreases in risk are by no means athletic. For example, women nurses in the highest activity group undertook 21 MET-h/week (Martínez et al. 1997). Brisk walking demands about 4-5 MET, thus, about $4-5 \mathrm{~h}$ of this activity weekly (possibly in addition to the routine demands for occupational walking in nursing) may be sufficient to reduce the risk of colon cancer. As with so many health benefits, however, it seems likely that more activity confers more benefit, at least up to some undefined threshold. For example, in the Health Professionals Follow-up Study, there was a linear relationship between activity level and the risk of colon cancer up to $46.8 \mathrm{MET}$-h/week, the 90 th centile among this group of men (Giovannucci et al. 1995).

From the public health viewpoint, a secondary analysis (Colditz et al. 1997) of these data (Giovannucci et al. 1995) is important. The median level of physical activity among these men was equivalent to $1 \mathrm{~h}$ running, $2 \mathrm{~h}$ tennis or $3 \mathrm{~h}$ walking/week. Colditz et al. (1997) suggest that, if $3 \mathrm{~h}$ of walking were added to the activity of all study participants, a $17 \%$ decrease in colon cancer might be expected. This interpretation fits well with that of Levi et al. (1999) who, using data from their case-control study, estimated that about one-fifth of colon cancer could be avoided by shifting the activity level of the entire population to the median level of activity they recorded (2-4h/week; no information on intensity). Thus, physical activity emerges as one of a few modifiable risk factors for some cancers, and may be particularly important for colon cancer.

\section{References}

Ainsworth BE, Sternfeld B, Slattery ML, Daguisé V \& Zahm SH (1998) Physical activity and breast cancer. Evaluation of physical activity assessment methods. Cancer 83, Suppl., 611-620.

Ballor DL \& Keesey RE (1991) A meta-analysis of the factors affecting exercise-induced changes in body mass, fat mass and fat-free mass in males and females. International Journal of Obesity 15, 717-726.
Bernstein L, Henderson BE, Hanisch R, Sullivan-Halley J \& Ross RK (1994) Physical exercise and reduced risk of breast cancer in young women. Journal of the National Cancer Institute $\mathbf{8 6}$, 1403-1408.

Bernstein L \& Ross RK (1998) Re: Physical activity and breast cancer risk in a cohort of young women. Journal of the National Cancer Institute 90, 1907-1908.

Broocks A, Pirke KM, Schweiger U, Tuschl RJ, Laessle RG, Strowitzki E, Hörl T, Haas W \& Jeschke D (1990) Cyclic ovarian function in recreational athletes. Journal of Applied Physiology 68, 2083-2086.

Bullen BA, Krinar GS, Beitins IZ, von Mehring G, Turnbull BA \& McArthur JW (1985) Induction of menstrual disorders by strenuous exercise in untrained women. New England Journal of Medicine 312, 1349-1353.

Colditz GA, Cannuscio CC \& Frazier AL (1997) Physical activity and reduced risk of colon cancer: implications for prevention. Cancer Causes and Control 8, 649-667.

Cordain L, Latin RW \& Behnke JJ (1986) The effects of an aerobic running program on bowel transit time. Journal of Sports Medicine 26, 101-104.

Després J-P (1994) Dyslipidaemia and obesity. Baillière's Clinical Endocrinology and Metabolism 8, 629-660.

Dorgan JF, Brown C, Barrett M, Splansky GL, Kreger BE, D'Agostino RB, Albanes D \& Schatzkin A (1994) Physical activity and risk of breast cancer in the Framingham Heart Study. American Journal of Epidemiology 139, 662-669.

Dosemeci M, Hayes RB, Etter R, Hoover RN, Tucker M, Engin K, Unsal M \& Blair A (1993) Occupational physical activity, socioeconomic status, and risks of 15 cancer sites in Turkey. Cancer Causes and Control 4, 313-321.

Enger SM, Longnecker MP, Lee ER, Frankl HD \& Haile RW (1997) Recent and past physical activity and prevalence of colorectal adenomas. British Journal of Cancer 75, 740-745.

Friedenreich CM, Thune I, Brinton LA \& Albanes D (1998) Epidemiological issues related to the association between physical activity and breast cancer. Cancer 83, Suppl., 600-610.

Gammon MD, John EM \& Britton JA (1998) Recreational and occupational physical activities and risk of breast cancer. Journal of the National Cancer Institute 90, 100-117.

Gerharsson M, Floderus B \& Norell SE (1988) Physical activity and colon cancer risk. International Journal of Epidemiology 17, $743-746$.

Giovannucci E, Ascherio A, Rimm EB, Colditz GA, Stampfer MJ \& Willett WC (1995) Physical activity, obesity, and risk for colon cancer and adenoma in men. Annals of Internal Medicine 122, 327-334.

Giovannucci E, Colditz GA, Stampfer MJ \& Willett WC (1996) Physical activity, obesity, and risk of colorectal adenoma in women (United States). Cancer Causes and Control 7, 253-263.

Giovannucci E, Leitzmann M, Spiegelman D, Rimm EB, Colditz GA, Stampfer MJ \& Willett WC (1998) A prospective study of physical activity and prostate cancer in male health professionals. Cancer Research 58, 5117-5122.

Haapanen N, Miilunpalo S, Pasanen M, Oja P \& Vuori I (1997) Assocation between leisure time physical activity and 10-year body mass change among working-aged men and women. International Journal of Obesity 21, 288-296.

Hartman TJ, Albanes D, Rautalahti M, Tangrea JA, Virtamo J, Stolzenberg R \& Taylor PR (1998) Physical activity and prostate cancer in the alpha-tocopherol, beta-carotene (ATBC) cancer prevention study (Finland). Cancer Causes and Control $\mathbf{9}$, $11-18$.

Hill MJ (1999) Diet, physical activity and cancer risk. Public Health Nutrition 2, 397-401. 
Lee I-M, Paffenbarger RS \& Hsieh C-C (1991) Physical activity and the risk of developing colorectal cancer among college alumni. Journal of the National Cancer Institute 83, 1324-1329.

Levi F, Pasche C, Lucchini F, Tavani A \& La Vecchia C (1999) Occupational and leisure-time physical activity and the risk of colorectal cancer. European Journal of Cancer Prevention 8, 487-493.

Liu S, Lee I-M, Linson P, Ajani U, Buring JE \& Hennekens CH (2000) A prospective study of physical activity and risk of prostate cancer in US physicians. International Journal of Epidemiology 29, 29-35.

McKeown-Eyssen G (1994) Epidemiology of colorectal cancer revisited: are serum triglycerides and/or plasma glucose associated with risk? Cancer Epidemiology Biomarkers and Prevention 3, 687-695.

McMichael AJ \& Giles GG (1988) Cancer in migrants to Australia: extending the descriptive epidemiological data. Cancer Research 48, 751-756.

McTiernan A, Ulrich C, Slate S \& Potter J (1998) Physical activity and cancer etiology: associations and mechanisms. Cancer Causes and Control 9, 487-509.

Martínez ME, Giovannucci E, Spiegelman D, Hunter DJ, Willett WC \& Colditz GA (1997) Leisure-time physical activity, body size, and colon cancer in women. Journal of the National Cancer Institute 89, 948-955.

Martínez ME, Heddens D, Earnest DL, Bogert CL, Roe D, Einspahr J, Marshall JR \& Alberts DS (1999) Physical activity, body mass index, and prostaglandin $\mathrm{E}_{2}$ levels in rectal mucosa. Journal of the National Cancer Institute 91, 950-953.

Mezzetti M, La Vecchia C, Decarli A, Boyle P, Talamini R \& Franceschi S (1998) Population attributable risk for breast cancer: diet, nutrition, and physical exercise. Journal of the National Cancer Institute 90, 389-394.

Moradi T, Adami H-O, Bergström R, Gridley G, Wolk A, Gerhardsson M, Dosemeci M \& Nyrén O (1999) Occupational physical activity and risk for breast cancer in a nationwide cohort study in Sweden. Cancer Causes and Control 10, 423-430.

Neugut AI, Terry MB, Hocking G, Mosca L, Garbowski GC, Forde KA, Treat MR \& Waye J (1996) Leisure and occupational physical activity and risk of colorectal adenomatous polyps. International Journal of Cancer 68, 744-748.

Nieman DC, Nehlsen-Cannarella SL, Markoff PA, BalkLamberton AJ, Yang H, Chritton DBW, Lee JW \& Arabatzis K (1990) The effects of moderate exercise training on natural killer cells and acute respiratory tract infections. International Journal of Sports Medicine 11, 467-473.

Nieman DC \& Pedersen BK (1999) Exercise and immune function: recent developments. Sports Medicine 27, 73-80.

Pate RR, Pratt M, Blair SN, Haskell WL, Macera CA, Bouchard C, Buchner D, Ettinger W, Heath GW, King AC, Kriska A, Leon
AS, Marcus BH, Morris J, Paffenbarger RS, Patrick K, Pollock ML, Rippe JM, Sallis J \& Wilmore JH (1995) Physical activity and public health. A recommendation from the Centers for Disease Control and Prevention and the American College of Sports Medicine. Journal of the American Medical Association 273, 402-407.

Phillips RL \& Snowdon DA (1985) Dietary relationships with fatal colorectal cancer among Seventh-Day Adventists. Journal of the National Cancer Institute 74, 307-317.

Potter JD (1999) Colorectal cancer: molecules and populations. Journal of the National Cancer Institute 91, 916-932.

Powell KE, Thompson PD, Casperson CJ \& Kendrick JS (1987) Physical activity and the incidence of coronary heart disease. Annual Review of Public Health 8, 253-287.

Rockhill B, Willett WC, Hunter DJ, Manson JE, Hankinson SE, Colditz GA (1999) A prospective study of recreational physical activity and breast cancer risk. Archives of Internal Medicine 159, 2290-2296.

Rockhill B, Willett WC, Hunter DJ, Manson JE, Hankinson SE, Spiegelman D \& Colditz GA (1998) Physical activity and breast cancer risk in a cohort of young women. Journal of the National Cancer Institute 90, 1155-1160.

Scanga CB, Verde TJ, Paolone AM, Andersen RE \& Wadden TA (1998) Effects of weight loss and exercise training on natural killer cell activity in obese women. Medicine and Science in Sports and Exercise 30, 1666-1671.

Slattery ML, Potter J, Caan B, Edwards S, Coates A, Ma K-N \& Berry TD (1997) Energy balance and colon cancer - beyond physical activity. Cancer Research 57, 75-80.

Tavani A, Braga C, La Vecchia C, Conti E, Filiberti R, Montellaa M, Amadori D, Russo A \& Franceschi S (1999) Physical activity and risk of cancers of the colon and rectum: an Italian casecontrol study. British Journal of Cancer 70, 1912-1916.

Thune I, Brenn T, Lund E \& Gaard M (1997) Physical activity and the risk of breast cancer. New England Journal of Medicine 336, 1269-1275.

Thune I \& Lund E (1996) Physical activity and risk of colorectal cancer in men and women. British Journal of Cancer 73, $1134-1140$.

Verloop J, Rookus MA, van der Kooy K \& van Leeuwen FE (2000) Physical activity and breast cancer risk in women aged 20-54 years. Journal of the National Cancer Institute 92, 128-135.

Williamson DF, Madans J, Anda RF, Kleinman JC, Kahn HS \& Byers T (1993) Recreational physical activity and ten-year weight change in a US national cohort. International Journal of Obesity 17, 279-286.

Woods JA, Davis JM, Smith JA \& Nieman DC (1999) Exercise and innate immune function. Medicine and Science in Sports and Exercise 31, 57-66. 